\title{
THE USE OF SPRAYED CONCRETE IN THE STRENGTHENING OF EARTHQUAKE RISK BUILDINGS
}

\author{
J. M. Leuchars*
}

\begin{abstract}
SUMMARY
Sprayed concrete has become an accepted efficient strengthening system for the strengthening and upgrading of masonry earthquake risk buildings. The standard of sprayed concrete in New Zealand has improved greatly over the past five years and has now reached a stage where the finish achieved matches that of formed fair faced concrete. The current state of the art in New Zealand in the preparation, placement and finishing of the concrete is described.

The design of the sprayed concrete walls for earthquake loads is described with particular attention being paid to the Author's current practice for detailing and placement of reinforcing.
\end{abstract}

\begin{abstract}
Editor's Note: This paper was first published in the Proceedings of the 1988 Pacific Concrete Conference and is reprinted with the permission of the Cement and Concrete Association of New Zealand and the New Zealand Concrete Society.
\end{abstract}

\section{INTRODUCTION}

If strengthening systems for masonry buildings are to be successful in controlling damage and preventing collapse, the systems must act before the brick wall fails. This requires a system which is of comparable stiffness to the original masonry. The use of a sprayed concrete skin on all remaining masonry walls is an obvious way of providing a continuous backing to the masonry.

When the concrete skins are well distributed the walls can be maintained at a low stress level. This does not require a material which is of a particularly high grade, the intent being to keep concrete stresses and ductility demands to a minimum.

\section{LOADINGS}

Reference 1, "Recommendations and Guidelines for Classifying Interim Securing and Strengthening of Earthquake Risk Buildings", sets a Design Lateral Force of $\mathrm{F}=\mathrm{c}_{\mathrm{dE}} \mathrm{w}_{\mathrm{t}}$

where $\quad C_{\mathrm{dE}}=\mathrm{C} \times \mathrm{R} \times(\mathrm{SM})_{\mathrm{E}} \times \mathrm{R}_{\mathrm{E}}$

$$
C=\text { basic shear coefficient which }
$$
varies with seismic zone and the

\footnotetext{
* Smith Leuchars Ltd, Auckland, New Zealand
}

period of the structure

$$
\begin{aligned}
\left.{ }^{(S M)}\right)_{E}= & \text { the structural type and material } \\
& \text { factor } \\
\mathrm{R}_{\mathrm{E}}= & \begin{array}{l}
\text { Reduction factor based on occupancy } \\
\text { of building }
\end{array} \\
\mathrm{R}= & \begin{array}{l}
\text { Risk factor from Table } 4 \text { of NZS } \\
4203: 1984
\end{array}
\end{aligned}
$$

The (SM) factor for sprayed concrete has been set ${ }^{E}$ at 2 for both ductile and limited ductility design. The limited ductility design has a multiplier which increases the design shear forces further to a point at which little or no ductile shear action is required while ductile moment design is still possible. Due to the low aspect ratio of the walls of most masonry buildings, ductile flexural failure is often impossible so the higher shear loads of the limited ductility design are commonly used. For sprayed concrete masonry buildings with their extensive shear panels this is not normally a great problem.

The following is a description of the current state of the art in spray concreting as applied in New Zealand by our company.

\section{THE CONCRETE}

\section{Mix Design}

Most applicators have their own mix design to suit their own equipment. 
Fortunately the lower the water content in the mix the better it stays in place, so that the strength and shrinkage characteristics of the mix are enhanced by efforts to improve placement.

\section{Preparation of Surfaces}

Generally no reliance is made of composite masonry/concrete action. The masonry is treated as a tied veneer. It will obviously endeavour to act compositely but this is not relied upon. Consequently the brick/concrete interface does not have to be roughened or cleaned down to any great extent.

All loose or dummy plasterwork should be pulled off before spraying. This eliminates the possibility of grinding the plaster up in an earthquake and producing voids between the concrete and masonry.

It also eliminates the possibility of the loose plaster being knocked off and falling into the wet concrete when this is being sprayed up.

The plaster around each drilled dowel should be broken back. This ensures a tight dowel action between concrete and masonry.

The existing walls should be saturated 24 hours before spraying up of the concrete. This ensures that there is a reserve of moisture within the existing wall helping to prevent leaching of water and impairment of hydration of the sprayed concrete.

\section{Placement}

The placement of the concrete can be specified in great detail, but in the end the standard of the concrete is very much reliant on the skill of the nozzle man. current practice in New Zealand is to spray up without a compressed air hose man following behind which is standard practice in the USA. The intent is to clear away any loose or rebound material.

If a compressed air hose is used a large increase in spalled debris can be expected; with standard NZ practice about 5 to $10 \%$ bounceback can be expected. This can be relatively easily handled and does not make the site unworkable.

The merits of airblasting or cleaning can only be proven by testing of concrete cores. To date, cores taken in walls show a drop in strength from that specified but the concrete is generally well mixed and homogenous with few air voids.

The only way to prove the merit of airblasting would be parallel testing to sprayed walls both with and without airblasting.

Many concrete applicators use a two coat system of layering up the main body of the concrete in the first thickness and then appling a 'finishing coat'. Planes of weakness have not been found in cores taken through walls sprayed up in this manner but it does raise doubts as to the bond between the two layers. The benefit of the thinner second layer is to reduce the amount of material being used at the end of the operation when the finishing starts. It means that a greater area of wall can be finished off at the same time and at the same consistency and workability.

\section{Finishing}

The standard of finish which is now expected is radically different from that expected only a year or two ago.

All concrete has to be screeded off using preplaced screed rails and a wooden screed. The concrete is then floated off with wooden floats by hand. After the initial set has commenced, the surface may then be sponged by hand using damp sponges to provide an even texture. The tolerances expected are of the order of plus or minus $3 \mathrm{~mm}$.

\section{Shrinking and curing}

It has been found that even with no curing and control joints, the amount of shrinkage cracking is minimal and often non-existant. This is due to the low water/cement ratios used in the $\mathrm{mix}$ and by limiting the length of wall sprayed up in each pour. Generally it is liked to spray up complete walls with no crack control joints, often the geometry makes this quite feasible. otherwise control joints at 7 to 8 metre centres should be used.

The only time we have encountered even moderately widespread cracking was in some of the ground floor walls of Scots college. These were sprayed up during a very hot and dry February. The cracks were fairly minimal and were easily covered by the paint system specified.

We now specify either damp curing with a hessian curtain or a curing compound. The use of either hessian or polythene has to be watched carefully otherwise the finish to the concrete may be effected by abrasion. In many instances wet curing cannot be used as the run off water can cause too much disruption or damage in the existing building. In most cases the contractor has chosen a curing compound.

The paint system used can help to cover up deficiencies in the quality of the finish. We have used a multi-coat textured finish in situations where we wanted to obtain a uniform texture on gibraltar board walls, old plaster walls and new spray walls.

We have also used ordinary acrylic paints on the sprayed walls. The finish obtained is similar to a smooth wall coated with a sand filled textured finish.

\section{Testing}

The only method of testing the concrete which gives any confidence is the coring and testing of the finished wall. Current procedure is to specify cores and test cylinders from each pour. We find there is a reduction in strength between the cylinders and the cores. However, we have not found any cores giving strengths below $15 \mathrm{Mpa}$ at 28 days when $25 \mathrm{MPa}$ concrete is specified. 


\section{REINFORCING AND DETAILING}

\section{Thickness of Spray Walls}

Walls up to $300 \mathrm{~mm}$ thick, (we have done one retaining wall with $600 \mathrm{~mm}$ thickness), can be sprayed quite successfully in terms of getting the concrete up without creating cold joints horizontally. The minimum thickness we have used is $100 \mathrm{~mm}$. This is really a minimum for structural purposes. Thinner coatings can be used but these would have trouble taking face loads, unless they were used on two sides. It would then be better to have thin plastered skins both sides similar to thee New Zealand Ministry of Works test programme walls with fibre reinforced plaster on both faces of brick walls (ref 2).

If the outermost steel has more than 60-65m cover, it is difficult to stop slumping of the face concrete. This therefore limits the most effective thickness of singly reinforced walls to approximately 150 maximum and 100 minimum.

\section{Placement of Bars}

One of the most important factors in obtaining good solid concrete is to minimise the shielding effect from reinforcing. This means that two layers of steel in walls should not be used if possible. If this is necessary then the rear layers of steel should be lined up with the front layers, see Figure 1.

When the bars are staggered it is difficult to angle the spray in behind the rear bars. If the bars are slightly offset the situation is virtually worse than being completely offset.

Problems associated with shielding of bars seem to be lessening by the use of mixes now being used which are fairly "fatty" and allow a good initial "flow" of the material.

\section{spacing of Bars}

A maximum spacing of approximately $300 \mathrm{~mm}$ and a minimum of $100 \mathrm{~mm}$ should be used in singly reinforced walls. In doubly reinforced walls a minimum spacing of 150 $\mathrm{mm}$ should be used on the front face. The rear face bars may be spaced at equal or twice the spacing of the front face bars. Again the maximum spacing of front face bars is $300 \mathrm{~mm}$.

The use of $66 \mathrm{X}$ HRC mesh provides a good pattern of reinforcing and we are increasingly using a combination of bars and mesh. The bars provide the support which is necessary to the mesh while the mesh, with its smaller diameter bar proves less of an impedance to the spray and helps reduce bounceback and loss of material.

\section{Laps}

Contact laps of bars should be avoided as these increase shielding effects and therefore a poor standard of concrete bond at a critical point. Laps should be offset by half the bar spacing where possible, additional lap length should then be provided.

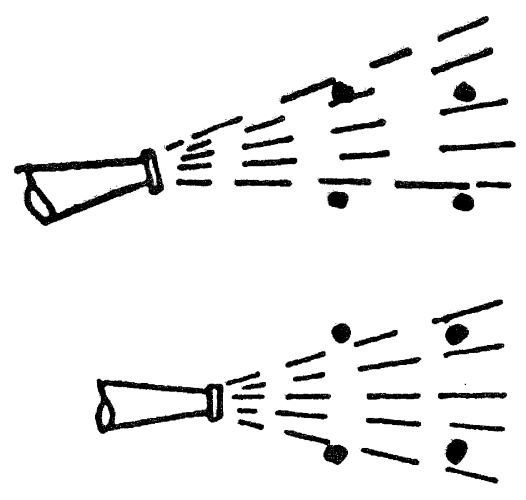

FIGURE 1 SPRAY SEQUENCES REQUIRED TO FILL BETWEEN BARS (TOP) AND TO FILL BEHIND BARS (BOTTOM)

Offsetting of laps makes lining up of front and back layers of reinforcing extremely difficult to coordinate. This is another factor forcing singly reinforced walls.

NB: As the bars used in spray concrete walls tend to be in the $10 \mathrm{~mm}$ to $20 \mathrm{~mm} \mathrm{bar}$ ranges. the strength of the concrete is not the governing factor in determining the lapD length. Standard lap lengths are set at $240, \mathrm{db}$ in equation $\mathrm{s}-2$ of NZS 3101 [3] for $f=25 \mathrm{kpa}$. Although we specify cylinder strengths of 20 or $25 \mathrm{Mpa}$ we have found that generally core tests have given strengths as low, as $16 \mathrm{kpa}$. We therefore use a reliable $f_{c}=15 \mathrm{Mpa}$ for stress and bond checks.

This requires the use of Eq. 5-6 of 3101 However the resulting lap lengths are still governed by $240 \mathrm{db}$, or 300 minimum lap lengths, even using $\mathrm{f}_{\mathrm{c}}=15 \mathrm{Mpa}$.

\section{Anchorages}

When bars are anchored off at critical locations the bar lengths used should be generous. An example is where the bars are run through existing walls to tie new sprayed walls on both sides of the existing wall, see Figure 2 .

We have often gone to the extent of putting a 180\# standard hook on one end of these bars.

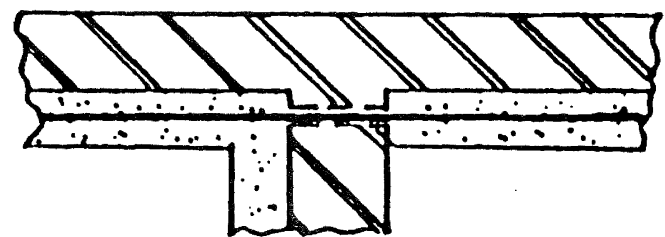

FIGURE 2 


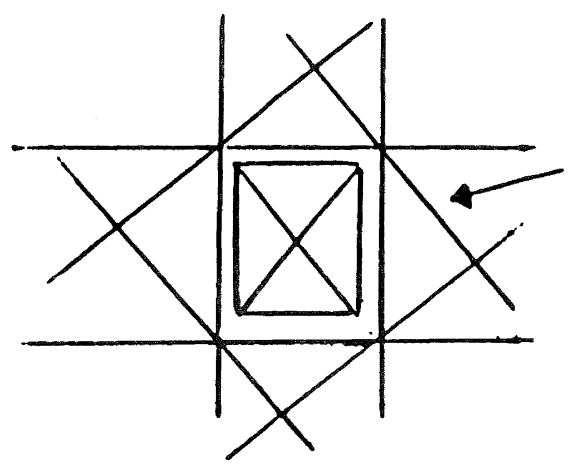

Trimming at openings

The normal practice of providing trim bars around openings should be followed. It is generally preferable to use diagonal corner trims where possible in addition to the normal rectangular grid of bars, see Figure 3.

Care has to be taken with the layout of diagonal bars. If the ends of the diagonal bars cross over, difficulties with concrete covers may occur. Diagonal bars are possible when $150 \mathrm{~mm}$ thick walls or greater are used. It is virtually impossible to use diagonal bars in $100 \mathrm{~mm}$ thick walls.

As the exact location of the reinforcing may vary from location to location depending on the accuracy of the original brickwork, the dowel placement and the steel fixing - some tolerance in steel placement - say $10 \mathrm{~mm}$, should be allowed for in detailing and design, see Figure 3 .

\section{Dowels}

We have used chemset epoxied and cement grouted dowels. The chemset anchors tend to give a more positive result and tests have shown that $12 \mathrm{~mm}$ bars anchored into sound brickwork give pullout strengths of approximately $20 \mathrm{KN}$. We have found that chemsets do not work when the anchor is set into porous material. The epoxy tends to run away into the material and insufficient epoxy is left to grip the bar. When some chemset anchors are torqued up, they have simply rotated in the hole after some nominal initial resistance. It is therefore wise to test some anchors in the existing walls early on in the project.

An alternative to chemsets is mechanically placed epoxies. It is often impossible to pour epoxies into holes unless these are vertical and of reasonable diameter. One system which gives a reasonable filling of epoxy has an outer tube which is filled with epoxy and then an inner solid rod is used to inject the epoxy into the hole. Horizontal dowels should be detailed with a downward angle of $15 \#$.

Another system, utilised on the redevelopment of the old Ferry Building in Auckland was the use of large diameter holes (50-60 mm) and cementious hand placed grouts.
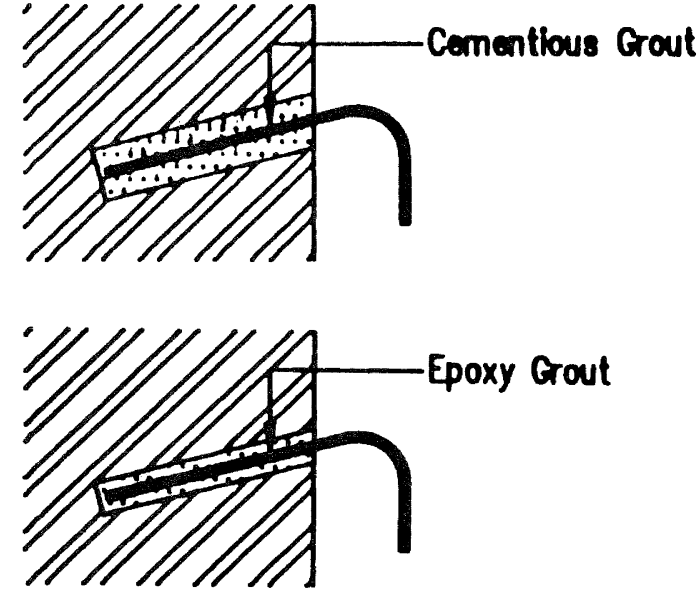

FIGURE 4

The shear capacity of the dowels is generally governed by the new material/existing material interface. The stress on the interface which is proportional to contact area, can be reduced by the use of the cheaper cementious grouts and larger diameter holes (see Figure 4)

The main problem with hand placed epoxies or cementitious grouts is that they rely on the skill and perseverance of the operator. As such there is always the chance of the operator producing a sloppy job. It is advisable to make random checks on the anchors by applying a torque to them.

As the spacing of these anchors is set to a maximum of 900 to $1100 \mathrm{~mm}$ centres, each dowel is unlikely to be stressed to more than $60 \%$ of its ultimate load.

A section of double skin brickwork with a weight of, say $0.25 \times 22=5.5 \mathrm{kN} / \mathrm{m}$ and a $\mathrm{Cp} \max$ of 2.0 gives a maximum load per dowel of $11 \mathrm{KN}$ which is close to the minimum reliable strength.

The spacing of 1000 to $1100 \mathrm{~mm}$ centres is therefore based on the strength of the anchors but is also a maximum practicable spacing to give a reinforcing grid which is rigid enough when hit by the sprayed concrete. 


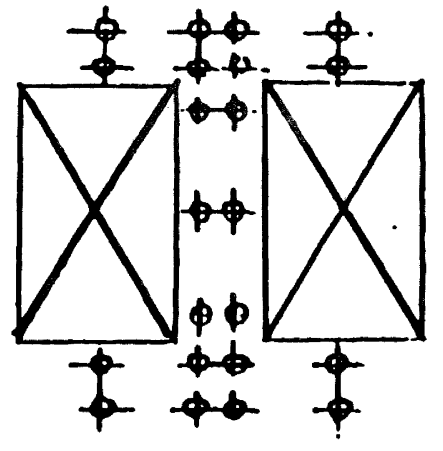

FIGURE 5 DOWEL PATTERN AT NARROW MULLION

The spacing of dowels is also governed by the geometry of the wall. often the spacings are reduced to well below the 1100 $\mathrm{mm}$ maximum due to the available width of walls between windows or doors being restricted.

A closer pattern of dowels should be used in areas where the brickwork may be expected to fracture. Examples would be at the top and bottom of mullions where column hinging may occur (see Figure 5).

Dowels should be used where vertical reinforcing is cranked over in line. This situation should be avoided where possible (see Figure 6).

\section{CONCLUSION}

The use of sprayed concrete as a seismic strengthening system is now generally accepted. The shortcoming of the material being its reliance on the skill of the applicators, can be catered for by designing structural systems which do not concentrate the seismic resistance on a small number of highly stressed elements. Instead a lowly stressed, well distributed structural system will place limited strength and ductility requirements on a large number of elements.
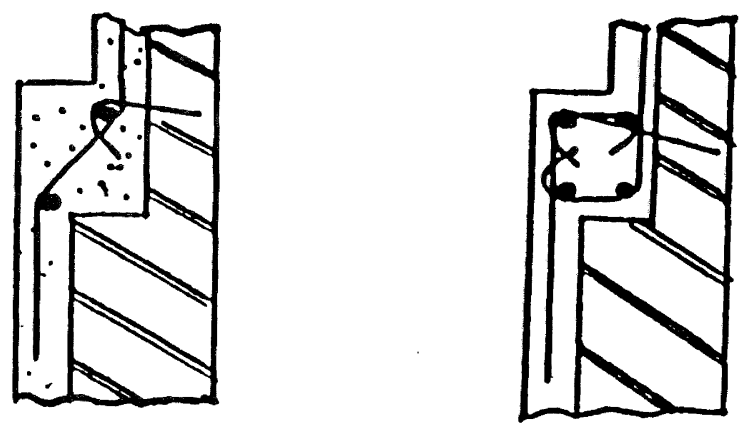
$\begin{array}{ccc}\text { FIGURE } & \text { DETAIL AT CRANK (LEFT) WITH } \\ \text { PREFERRED DETAIL (RIGHT) } & \text { (RHT }\end{array}$

\section{REFERENCES}

1. New Zealand National Society for Earthquake Engineering Study Group on "Recommendations and Guidelines for Classifying Interim Securing and Strengthening of Earthquake Risk Buildings" December 1985.

2. Hutchinson, DL, Yong, PMF, and McKenzie GHF. 1984. Laboratory Testing of a Variety of strengthening solutions for Brick Masonry Wall Panels". 8th World Conference on Earthquake Engineering.

3. Standards Association of New Zealand. 1982. "Design of Concrete Structures". NZS 3101 . 